\title{
Probing the Surface of a Parasite Drug Target Thioredoxin Glutathione Reductase using Small Molecule Fragments
}

Francesca Fata ${ }^{+1}$, Ilaria Silvestri ${ }^{1}$, Matteo Ardini†, Rodolfo Ippoliti†, Luana Di Leandro†, Nicola Demitri§, Maurizio Polentarutti ${ }^{\S}$, Adele Di Matteo $^{\circ}$, Haining Lyu‡, Gregory R.J. Thatcher^, Pavel A. Petukhov ${ }^{\star}$, David L. Williams **, Francesco Angelucci†*.

†Dept. of Life, Health and Environmental Sciences, University of L'Aquila, 67100 L'Aquila, Italy

‡Dept. of Microbial Pathogens and Immunity, Rush University Medical Center, Chicago, IL 60612, USA

§Elettra - Sincrotrone Trieste, S.S. 14 Km 163.5 in Area Science Park, 34149 Basovizza - Trieste, Italy

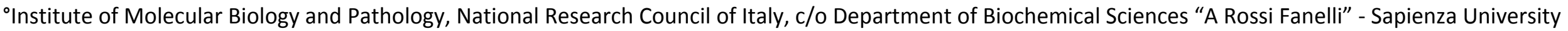
of Rome, 00185 Rome, Italy

${ }^{\triangle}$ Dept. of Pharmaceutical Sciences, College of Pharmacy, University of Illinois at Chicago, Chicago 60612, IL USA

${ }^{\perp}$ Dept. of Pharmacology \& Toxicology, College of Pharmacy, the University of Arizona, Tucson 85721, AZ USA

\section{Corresponding Author Information}

*Francesco Angelucci: francesco.angelucci@univaq.it

*David L. Williams: david williams@rush.edu 
Table S1. Chemical structures of the other fragments tested in this work (shown as dominant ionization state at $\mathrm{pH}=7.4, \mathrm{pK} \mathrm{a}_{\mathrm{a}}$ calculations have been carried out at http://chemicalize.com). CID 39450, CID 4276005 and CID224037 likely form imine methide or quinone methide electrophilic species, ${ }^{1}$ upon release of the positively charged secondary amines, and thus can potentially interfere with DTNB assay covalently interacting with the free thiol of the TNB product as well as with the nucleophilic centers of the enzyme.

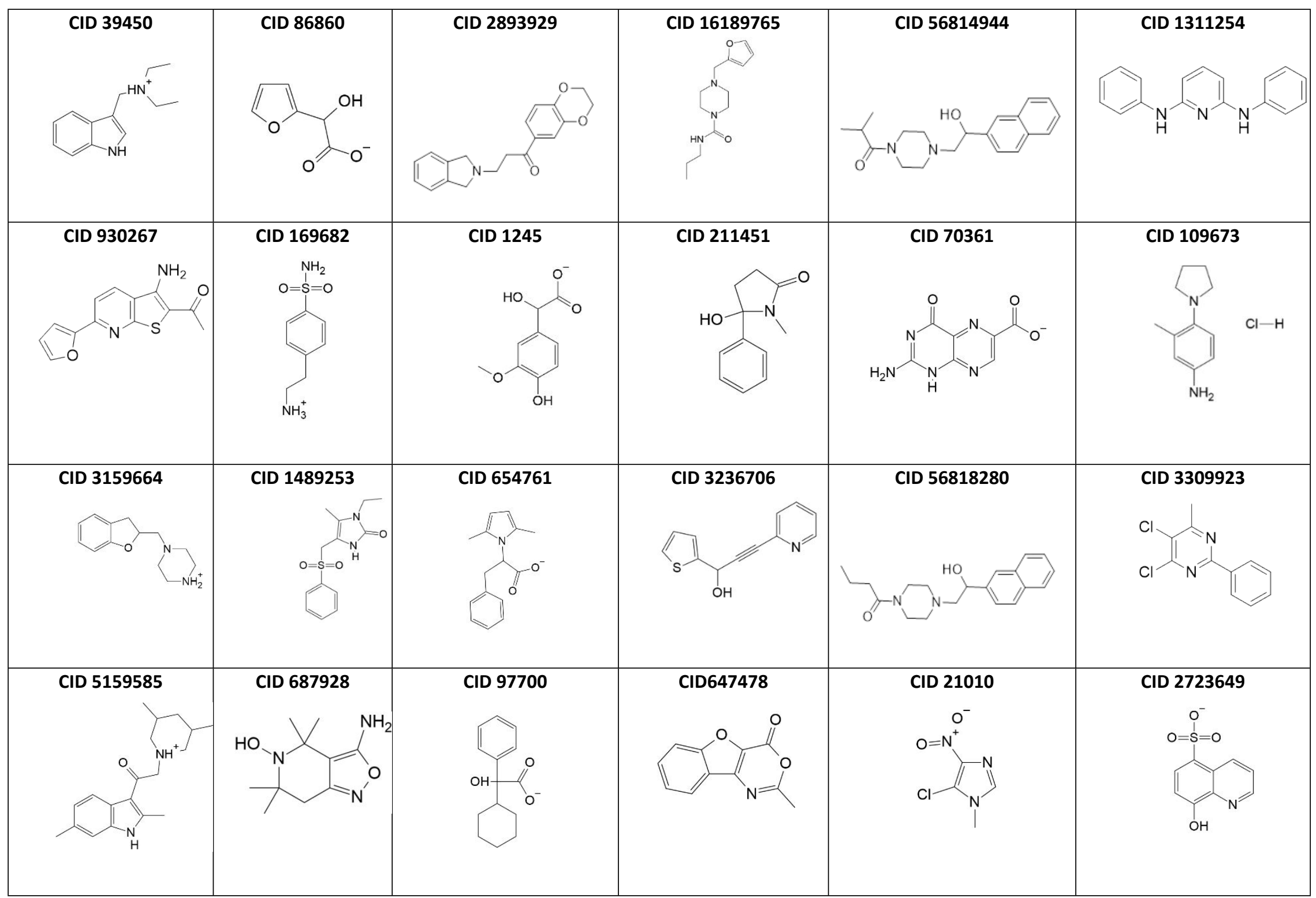




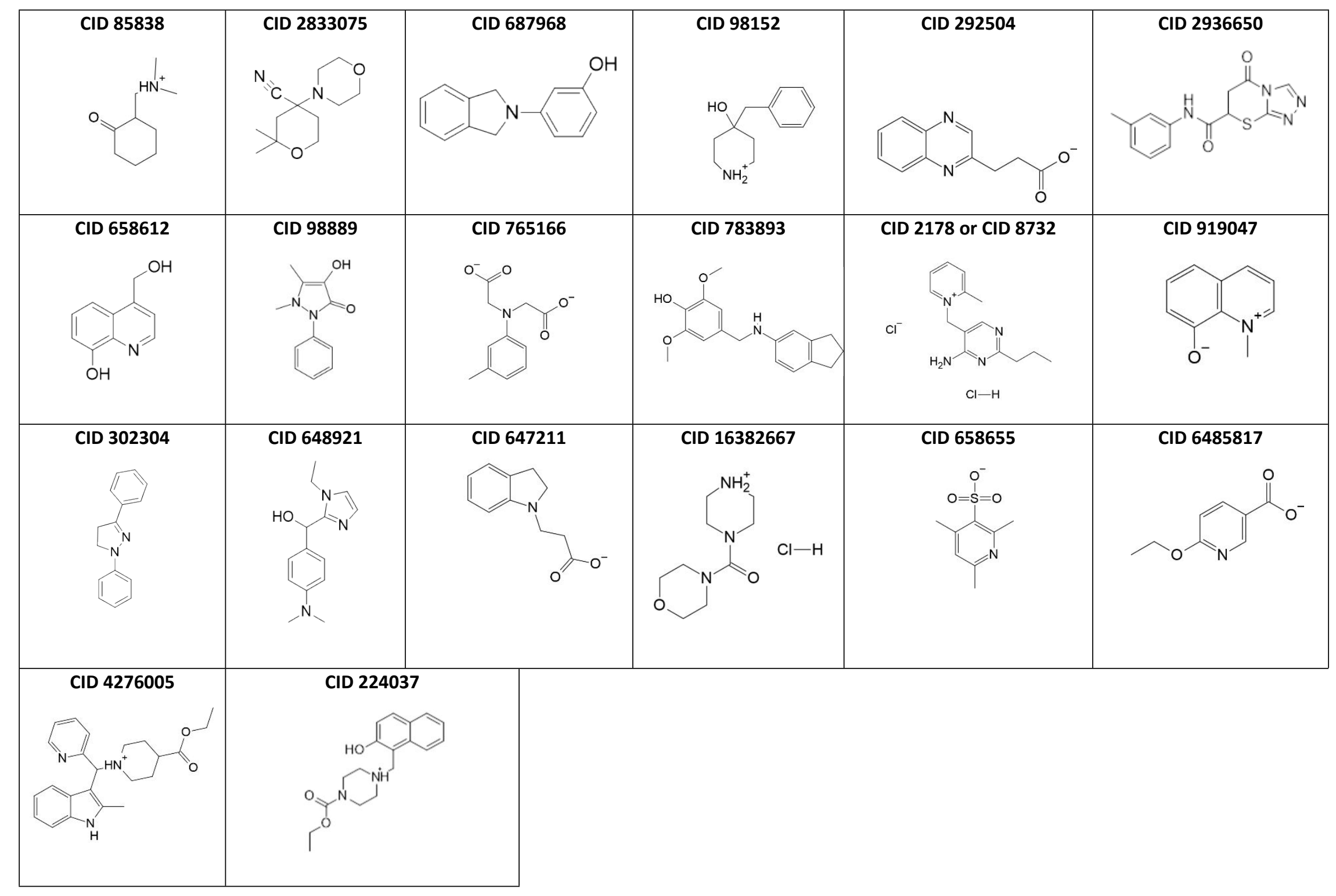


Table S2. Summary of X-ray data reduction and structural refinement statistics.

\begin{tabular}{|c|c|c|c|c|c|c|}
\hline Compound & $\begin{array}{l}1 \mid 3-(3- \\
\text { methoxyquinoxalin-2-yl) } \\
\text { propanoic acid; } \\
\text { cocrystallization at } \\
12.5 \mathrm{mM}\end{array}$ & $\begin{array}{l}\text { 1|3-(3- } \\
\text { methoxyquinoxalin-2- } \\
\text { yl) propanoic acid; } \\
\text { soaking for } 24 \mathrm{~h} \text { at } \\
25 \mathrm{mM}\end{array}$ & $\begin{array}{l}\text { 2|2-Methylindole-3- } \\
\text { acetic acid; soaking } \\
\text { for } 96 \mathrm{~h} \text { at } 25 \mathrm{mM}\end{array}$ & $\begin{array}{l}3 \mid 2,1,3- \\
\text { benzothiadiazol-4- } \\
\text { amine; soaking for } \\
24 \mathrm{~h} \text { at } 25 \mathrm{mM}\end{array}$ & $\begin{array}{l}4 \mid \text { Indole-3-carbinol; } \\
\text { soaking for } 24 \mathrm{~h} \text { at } \\
25 \mathrm{mM}\end{array}$ & $\begin{array}{l}\text { 5| 4-Hydroxy-7- } \\
\text { methyl-1,8- } \\
\text { naphthyridine-3- } \\
\text { carboxylic acid; } \\
\text { soaking for } 24 \mathrm{~h} \text { at } \\
25 \mathrm{mM}\end{array}$ \\
\hline $\begin{array}{l}\text { PDB IDS } \\
\text { DATA REDUCTION } \\
\text { STATISTICS }\end{array}$ & 6ZST & 7NPX & $6 Z \mathrm{PP}$ & 6ZLP & 6ZLB & 7B02 \\
\hline Space group & $\mathrm{C} 2$ & P 212121 & $\mathrm{C} 2$ & $\mathrm{C} 2$ & $\mathrm{C} 2$ & $\mathrm{C} 2$ \\
\hline Unit cell dimensions (Å) & $\begin{array}{lll}142.7 & 102.7 & 58.7 \\
\beta=113.0 & \end{array}$ & 84.2787 .93185 .41 & $\begin{array}{lll}141.8 & 102.2 \quad 58.6 \\
\beta=112.9 & \end{array}$ & $\begin{array}{lll}143.0 & 101.8 & 58.5 \\
\beta=112.9 & \end{array}$ & $\begin{array}{lll}147.7 & 101.8 & 60.4 \\
\beta=113.1 & \end{array}$ & $\begin{array}{l}142.8102 .458 .9 \\
\beta=112.8\end{array}$ \\
\hline Resolution range $(\AA ̊)$ & 39.9-1.7 (1.73-1.70)* & $39.73-2.70(2.82-2.7)$ & $39.68-1.8(1.84-1.8)$ & $39.84-2.15(2.22-2.15)$ & $37.54-1.90(1.94-1.90)$ & $39.93-1.45$ (1.47-1.45) \\
\hline mean I/sigma(I) & $11.5(2.5)$ & $13.4(2.1)$ & $14.2(2.6)$ & $11.4(2.2)$ & $14.0(2.3)$ & $9.2(1.9)$ \\
\hline Completeness (\%) & $97.7(96.5)$ & $99.8(98.4)$ & 98.9 (99.9) & 99.8 (99.9) & 99.1 (96.2) & $98.6(86.1)$ \\
\hline $\mathrm{CC} 1 / 2(\%)$ & $99.6(80)$ & $99.8(78.2)$ & 99.9 (76.9) & $99.8(73)$ & $99.8(77.5)$ & $99.8(63)$ \\
\hline Rmerge (\%) & $7.6(54.5)$ & $11.9(97.0)$ & $6.1(54.6)$ & $7.2(63.8)$ & $5.4(49.6)$ & $5.3(48.3)$ \\
\hline $\begin{array}{l}\text { Number of unique } \\
\text { reflections }\end{array}$ & 83411 (4363) & 38527 (4577) & 70295 (4221) & 41931 (3658) & 64112 (4009) & 135935 (5849) \\
\hline Redundancy & $3.8(3.9)$ & $7.4(4.5)$ & $4.4(4.5)$ & $4.8 .8(4.9)$ & $3.8(3.6)$ & $3.6(2.5)$ \\
\hline $\begin{array}{l}\text { REFINEMENT STATISTICS } \\
\text { Resolution range }(\AA)\end{array}$ & 39.93-1.7 (1.74-1.70) & $39.76-2.7(2.77-2.7)$ & $39.68-1.8(1.82-1.8)$ & $37.0-2.15(2.2-2.15)$ & $37.0-1.9$ (1.93-1.90) & 39.93-1.45 (1.49-1.45) \\
\hline No. reflections & 79198 (5796) & $36460(2608)$ & 70291 (2598) & 41923 (2680) & $64098(2527)$ & $129182(8543)$ \\
\hline
\end{tabular}




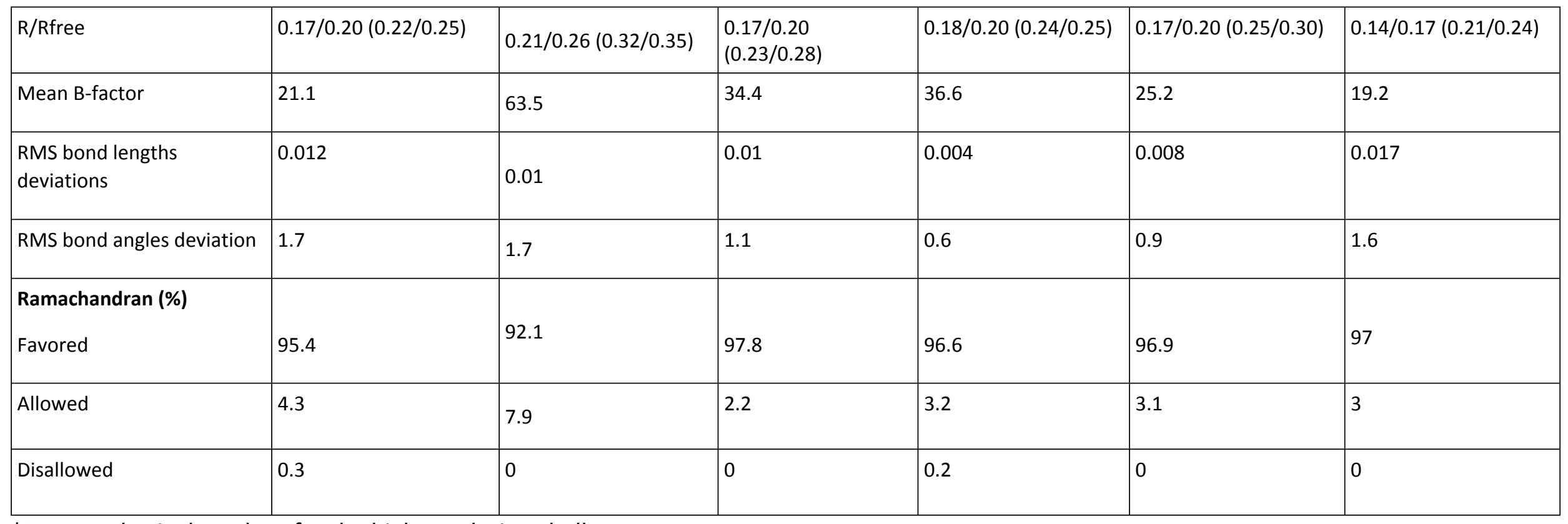

*In parenthesis the values for the high-resolution shells 
Table S3. B-factor analysis, estimated occupancy and RSCC values of the compounds bound to SmTGR presented in this study. All the $\mathrm{B}_{\text {ligand }} / \mathrm{B}_{\text {surroundings }}$ ratio are below 2 and most are close to 1 , indicating genuine protein-ligand complexes. ${ }^{2}$ In general, large discrepancy in the $\mathrm{B}$ factor of the ligand and that of the surroundings indicates that the ligand is either present at partial occupancy or that its presence is not supported by electron density. The structure of SmTGR in complex with 1, co-crystallized at 12.5mM (PDB ID: 6ZST), has the higher B-factor ratio, indicating that the compound is present at partial occupancy, as also reflected by its suboptimal initial Fo-Fc electron density (see Figure S2, Panel A). However, the structure of SmTGR obtained by soaking 1 at twice the concentration used in co-crystallization (PDB ID: 7NPX), presents better values of the Bfactor ratio and better initial electron density (Figure S2, panel B and C), further confirming the presence of 1 in that location. The occupancy of the ligands has been estimated considering the Background Density Correction (BDC) values derived from PanDDa analysis. This value correlates with the number of binding sites in the crystal that are not occupied by the ligand; the ligand occupancy is estimated as [2*(1-BDC)].3,4 All the RSCC are above 0.86 indicating a very good similarity between the model and the data. ${ }^{5}$

\begin{tabular}{|c|c|c|c|c|c|}
\hline $\begin{array}{l}\text { Structures of SmTGR complexes described in } \\
\text { this study }\end{array}$ & $\begin{array}{l}\text { B }_{\text {surroundings }} \text { (contacting } \\
\text { atoms within } 4 \AA \text { ) }\end{array}$ & $\begin{array}{l}B_{\text {Ligand }} \\
(100 \% \\
\text { occupancy })\end{array}$ & $\mathrm{B}_{\text {ligand }} / \mathrm{B}_{\text {surroundings }}$ & $\begin{array}{l}\text { Estimated occupancy from } \\
\text { the BDC values from PanDDa } \\
\text { [Occupancy }=(1-B D C) * 2] \text {. }\end{array}$ & RSCC \\
\hline $\begin{array}{l}\text { PDB ID: 6ZST } \\
\text { (compound } 1 \text { - cocrystallization at } 12.5 \mathrm{mM} \text {; Res }=1.7 \AA \text { ) }\end{array}$ & $34.9 \AA^{2}$ & $61.1 \AA^{2}$ & 1.7 & $64 \%$ & 0.87 \\
\hline $\begin{array}{l}\text { PDB ID: } 7 \mathrm{NPX} \\
\text { (compound } 1 \text { - soaking for } 24 \mathrm{~h} \text { at } 25 \mathrm{mM} \text {; Res }=2.7 \AA \text {; two } \\
\text { subunits in the a.s.u.) }\end{array}$ & $\begin{array}{l}56.0 \AA^{2} \\
73.5 \AA^{2}\end{array}$ & $\begin{array}{l}70.9 \AA^{2} \\
82.9 \AA^{2}\end{array}$ & $\begin{array}{l}1.3 \\
1.1\end{array}$ & n.d. & $\begin{array}{l}0.91 \\
0.93\end{array}$ \\
\hline $\begin{array}{l}\text { PDB ID: } 6 Z \text { P } 3 \\
\text { (compound } \mathbf{2} \text { - soaking for } 96 \mathrm{~h} \text { at } 25 \mathrm{mM} \text {; Res }=1.8 \AA \text { ) }\end{array}$ & $35.7 \AA^{2}$ & $43.5 \AA^{2}$ & 1.2 & n.d. & 0.90 \\
\hline
\end{tabular}




\begin{tabular}{|c|c|c|c|c|c|}
\hline $\begin{array}{l}\text { PDB ID: 6ZLP } \\
\text { (compound } 3 \text { - soaking for } 24 \mathrm{~h} \text { at } 25 \mathrm{mM} \text {; Res }=2.15 \AA \text { ) }\end{array}$ & $40.8 \AA^{2}$ & $46.6 \AA^{2}$ & 1.1 & $78 \%$ & 0.92 \\
\hline
\end{tabular}


Table S4. Normalized B-factors ( $\mathrm{B}^{\prime}$ ) of SmTGR in complex with 5 bound in Site3 and in apo-form. 5 induces stabilization of (i) the YTDG loop (374377; $\left.\Delta \mathrm{B}^{\prime}=-1.7\right)$, (ii) the $2 \beta$-strands (367-383; $\left.\Delta \mathrm{B}^{\prime}=-1.16\right)$, where residues contacting 5 lie, and (iii) the guiding bar residues $\left(518-519 ; \Delta \mathrm{B}^{\prime}=-0.46\right)$.

\begin{tabular}{|c|c|c|}
\hline Data collection & $\mathrm{B}^{\prime}$ factor 374-377 (367-383) & $\mathrm{B}^{\prime}$ factor 517-518 (guiding bar) \\
\hline 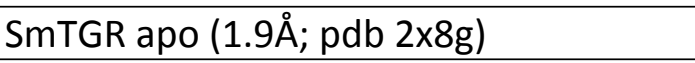 & $1.43(1.08) \AA^{2}$ & $-0.04 \AA^{2}$ \\
\hline SmTGR in complex with 5 in Site3 (1.6尺) & $-0.27(-0.08) \AA^{2}$ & $-0.51 \AA^{2}$ \\
\hline
\end{tabular}

$\mathrm{B}^{\prime}=(\mathrm{B}-\mu \mathrm{B}) / \sigma \mathrm{B} ;$ Normalized $\mathrm{B}$ - factor $\left(\mathrm{B}^{\prime}\right)$ is an expression of the $\mathrm{B}$-factor $(\mathrm{B})$ in units of standard deviation $(\sigma \mathrm{B})$ with respect to the mean value $(\mu \mathrm{B}) .^{6}$ 
A

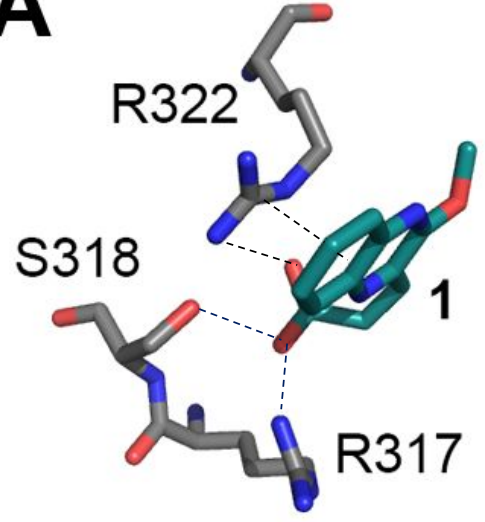

B

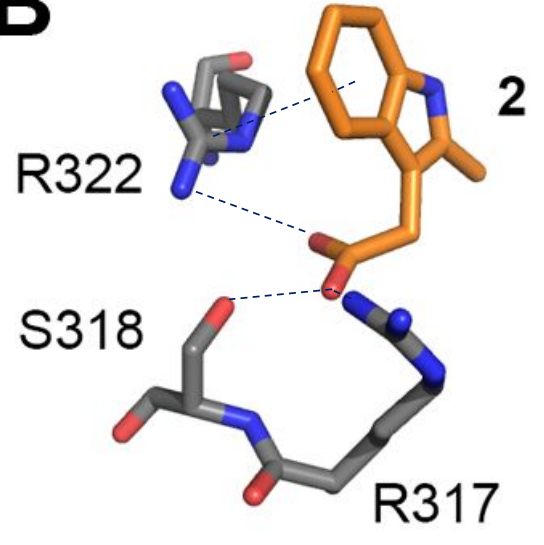

$\mathbf{C}_{\text {D334 }}$

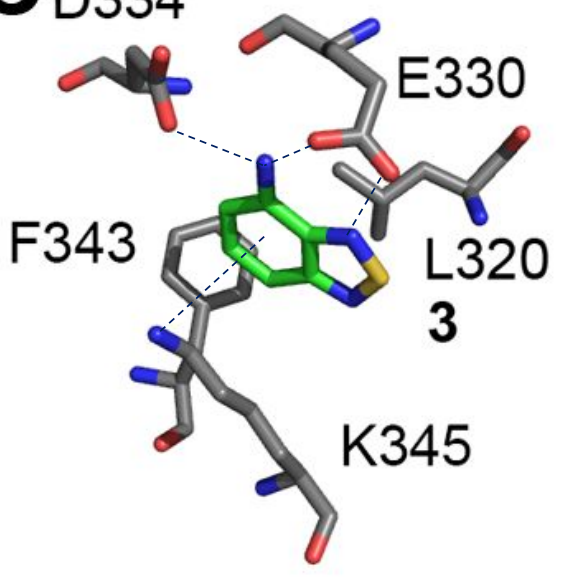

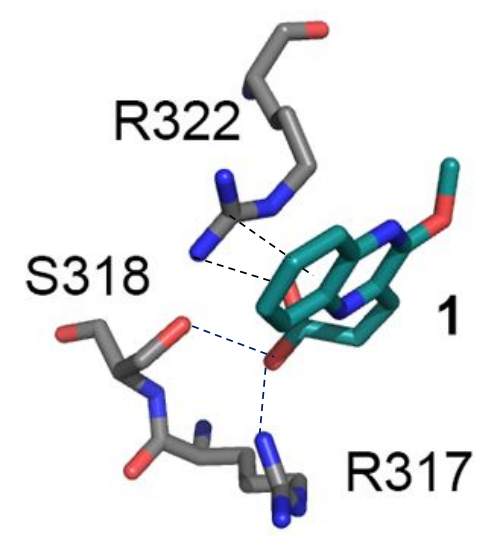
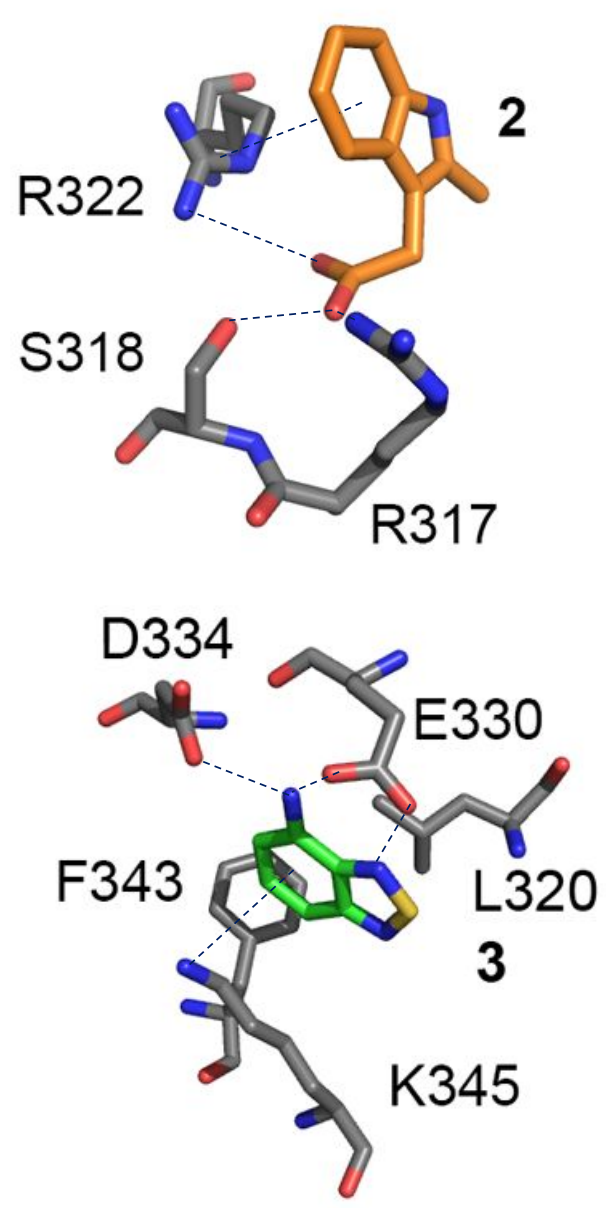

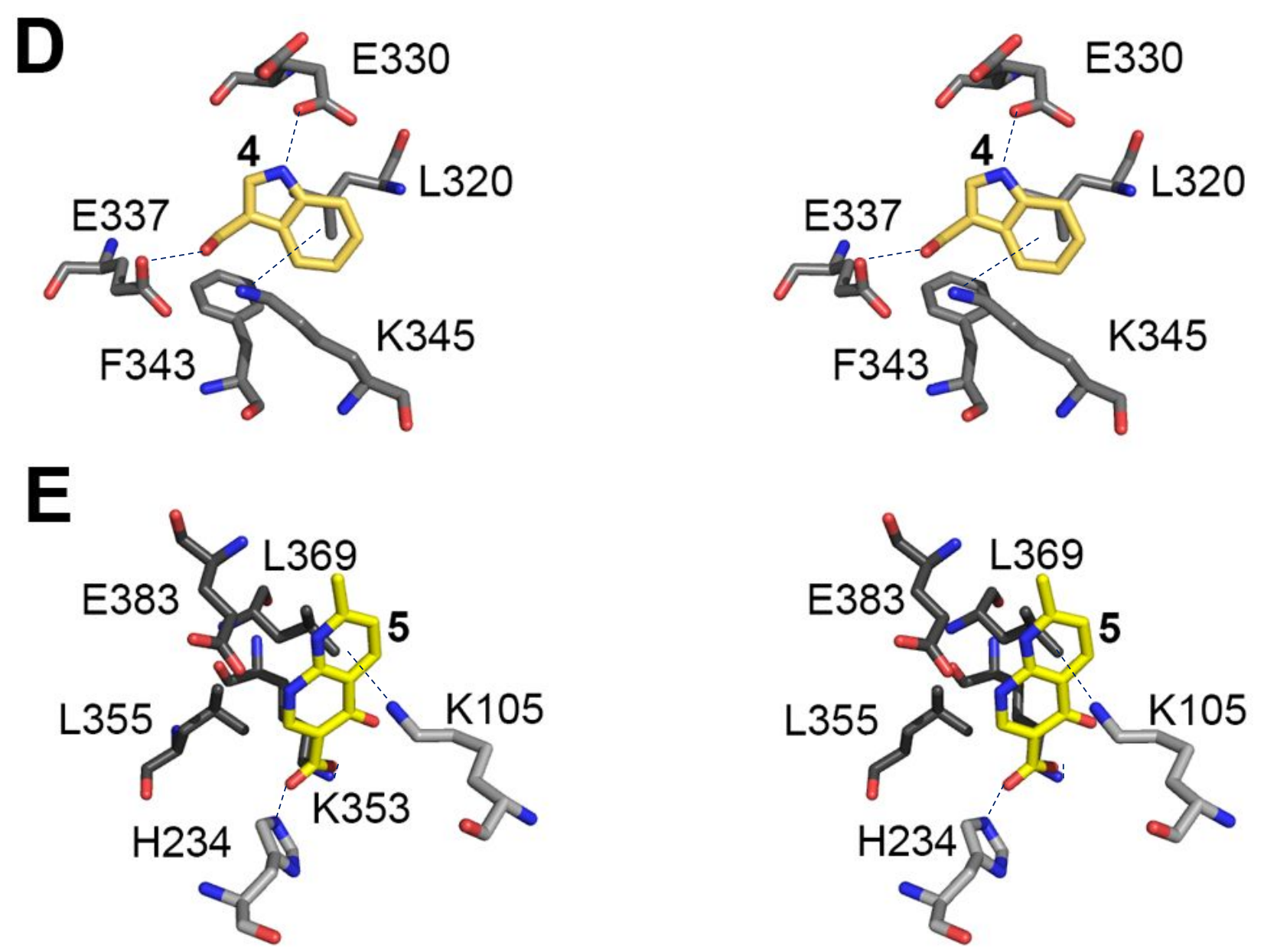

Figure S1. Stereo images of the compounds described in this study and their surrounding interacting residues. Amino acidic side chains interacting with compounds are in grey sticks and compounds are in sticks colored accordingly to the main text. Panel A: compound $\mathbf{1}$ in deep teal sticks; Panel B: compound $\mathbf{2}$ in orange sticks; Panel C; compound $\mathbf{3}$ in green; Panel D: compound $\mathbf{4}$ in gold sticks; Panel E: compound $\mathbf{5}$ in yellow sticks; in this latter panel, residues belonging to subunit " $c$ " are in deep grey, while in light grey are those belonging to subunit " $d$ " (see Figure 5 of the main text). Polar interactions are indicated as dotted lines. 

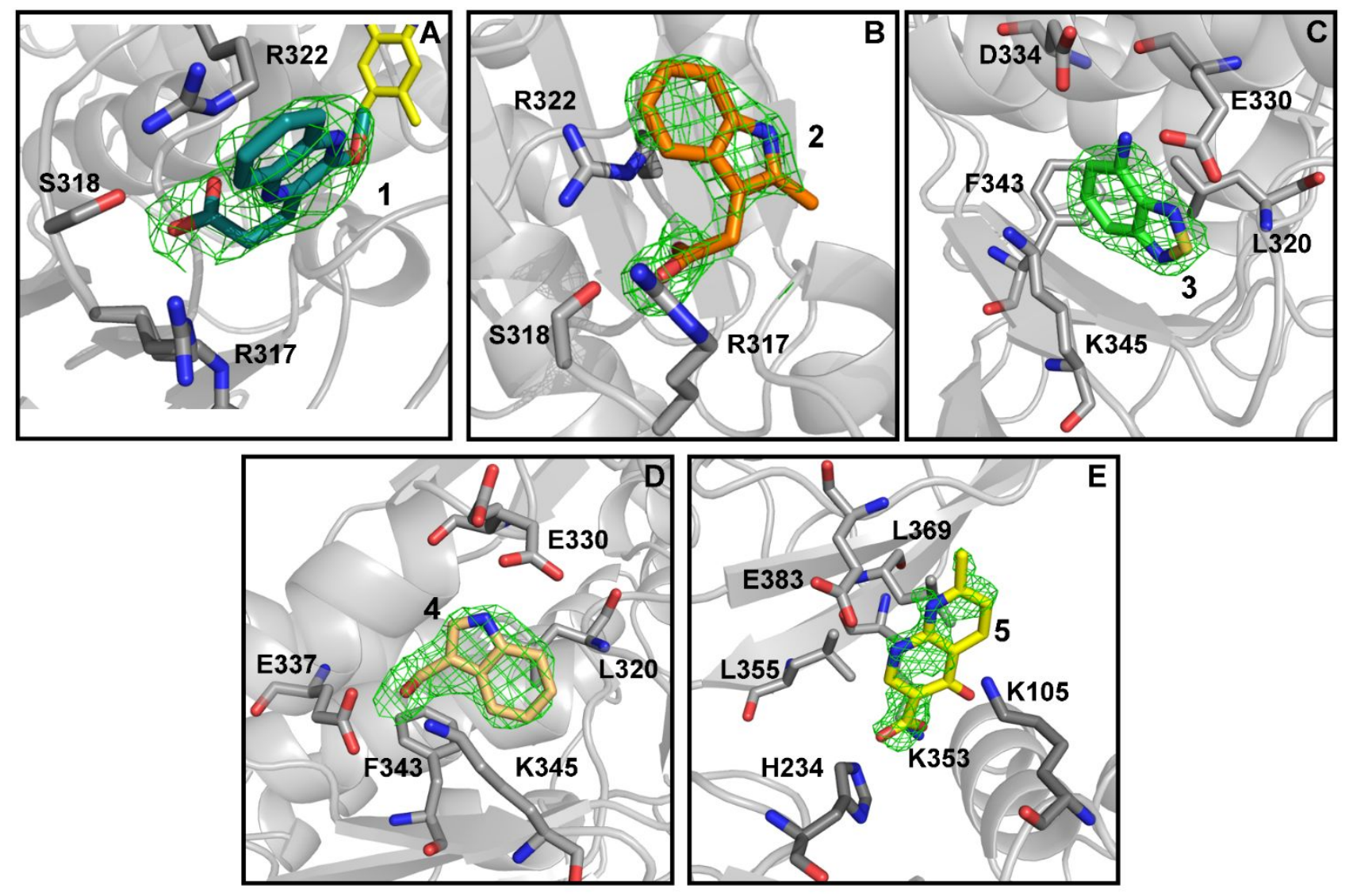

Figure S2. Fo-Fc electron density maps (omit maps) of the five compounds described in this study contoured at $3 \sigma$. Interacting residues are reported in grey, while compounds are in sticks colored according to their color code of the main text. Panel A: compound $\mathbf{1}$ in deep teal; Panel B: compound $\mathbf{2}$ in orange; Panel C; compound $\mathbf{3}$ in green; Panel D: compound $\mathbf{4}$ in gold; Panel E: compound $\mathbf{5}$ in yellow. 

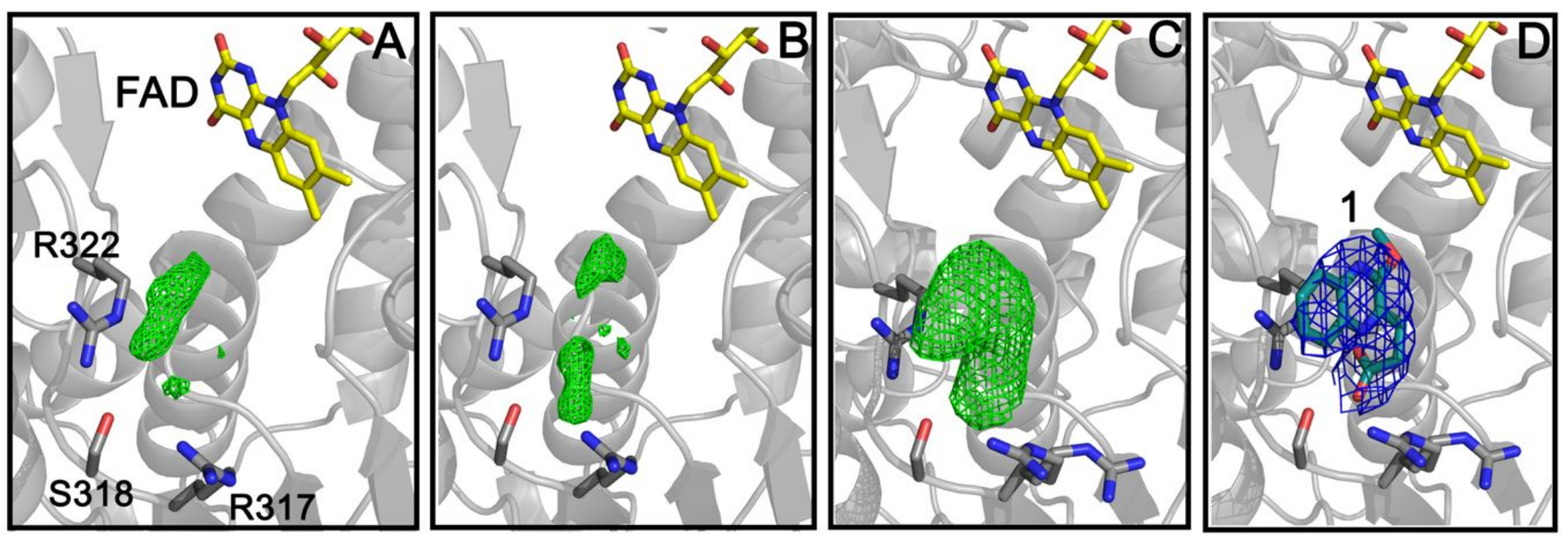

Figure S3. Electron density of compound 1 as improved by PanDDa and by a subsequent soaking experiment at higher concentration. In panels $A$ and $B$, the electron density of SmTGR crystals incubated with 1 in a co-crystallization experiments at 12.5mM (PDB ID: 6ZST); conventional Fo-Fc (Panel A) and improved PanDDa maps (Panel B) contoured at $3 \sigma$ are shown. In panels $C$ and D, the Fo-Fc and the 2Fo-Fc electron densities, contoured at $3 \sigma$ and at $1 \sigma$ respectively, of SmTGR crystals incubated with 2 at $25 \mathrm{mM}$ after 24 hours of soaking (PDB ID: 7NPX) are shown. 

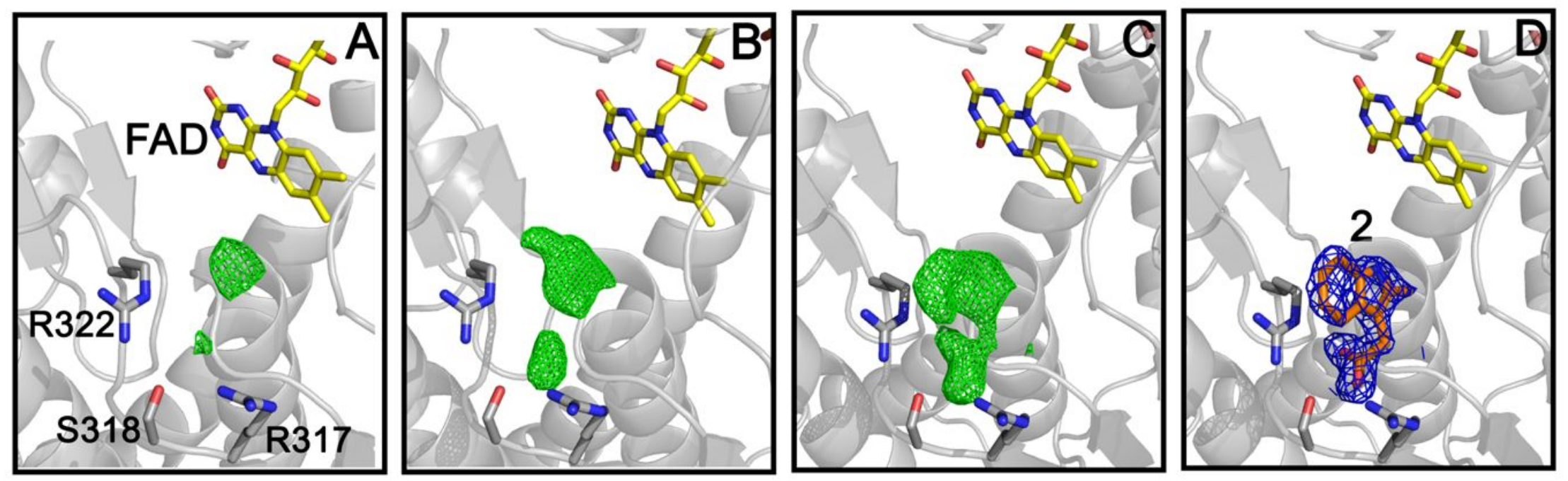

Figure S4. Electron density of compound $\mathbf{2}$ as improved by PanDDa and by longer soaking times. In panels A and B, the electron density of SmTGR crystals incubated with 2 after 72 hours of soaking (not deposited, 2.2A): conventional Fo-Fc (Panel A) and improved PanDDa maps (Panel B) contoured at $3 \sigma$ are reported. In panels $C$ and D, the Fo-Fc and the 2Fo-Fc electron densities, contoured at $3 \sigma$ and at $1 \sigma$ respectively, of SmTGR crystals incubated with 2 after 96 hours of soaking (PDB ID: 6ZP3) are shown. 

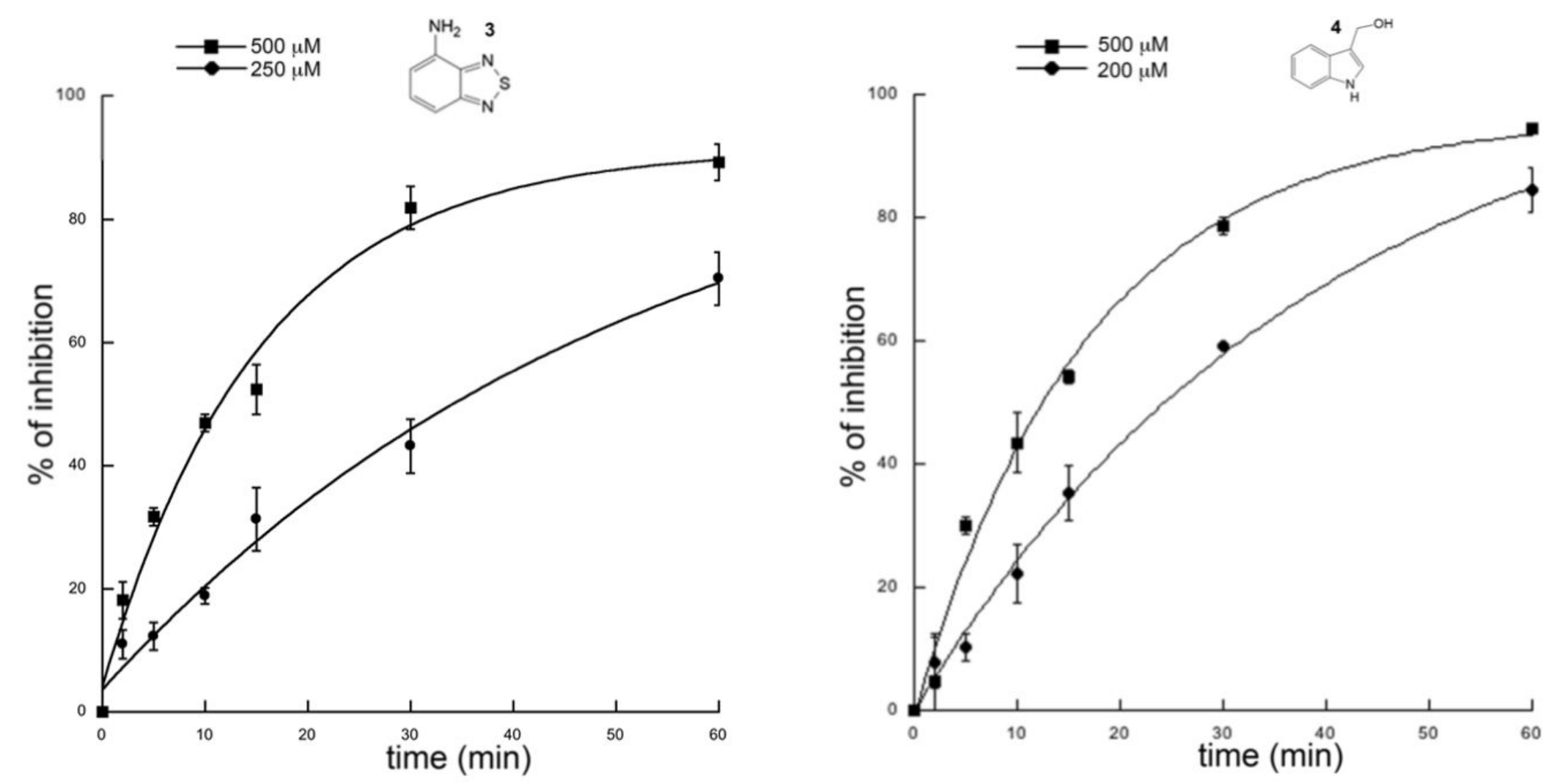

Figure S5. Time dependent inactivation of SmTGR WT by compounds 3 and $\mathbf{4}$. The experimental points are the averaged values derived from 3 to 6 independent experiments and were fitted with a first-order kinetic model.

SmTGR WT vs 3: $\mathrm{K}_{\text {inact }}(250 \mu \mathrm{M})=0.019 \mathrm{~min}^{-1} ; \mathrm{K}_{\text {inact }}(500 \mu \mathrm{M})=0.065 \mathrm{~min}^{-1}$

SmTGR WT vs 4: $\mathrm{K}_{\text {inact }}(200 \mu \mathrm{M})=0.026 \mathrm{~min}^{-1} ; \mathrm{K}_{\text {inact }}(500 \mu \mathrm{M})=0.059 \mathrm{~min}^{-1}$ 


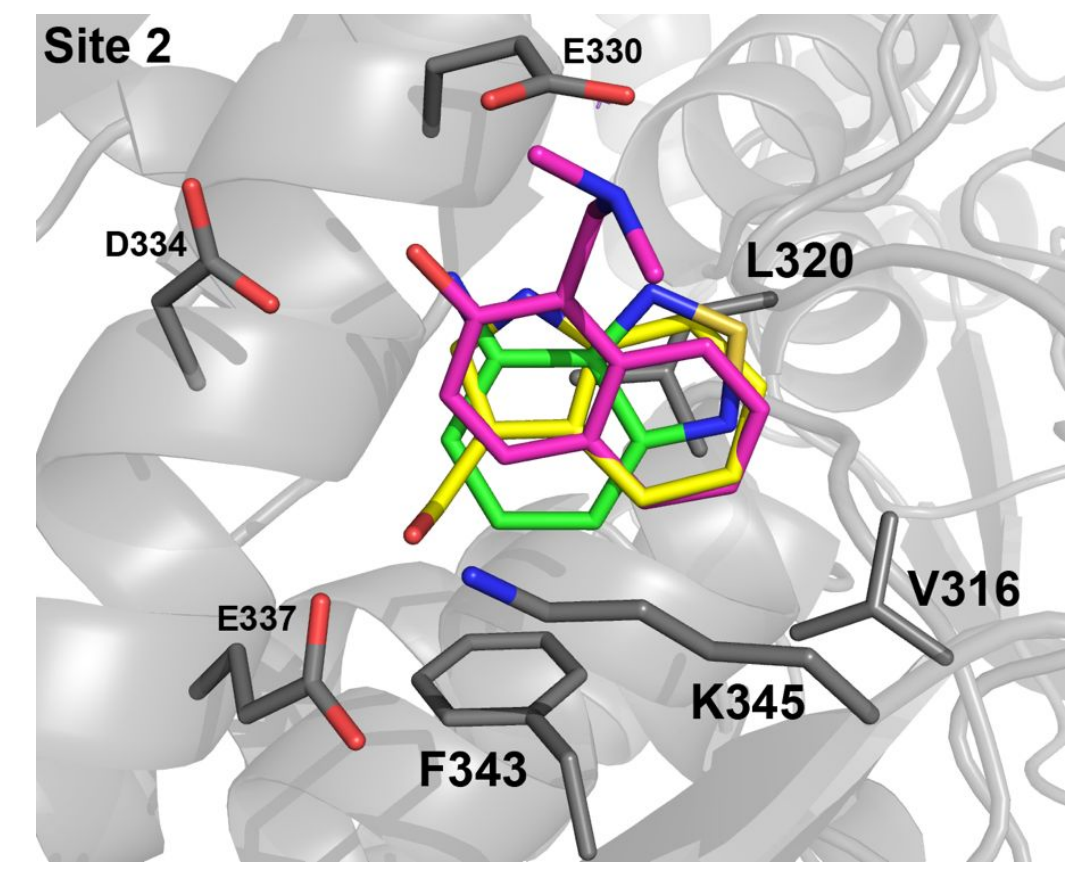

Figure S6. Superposition of SmTGR crystal structures in complex with compound 3, 4 (this study) and 1-[(Dimethylamino)methyl]-2-naphthol (PDB ID: 6RTJ). ${ }^{1}$ Compounds 3, 4 and the 2-naphtholmethylamino compound are in green, yellow and magenta sticks respectively. The interacting residues are in grey sticks and the protein is shown in transparent grey cartoons. The three compounds occupy a similar position in Site 2 , suggesting some possibilities for further optimize the 2-naphtholmethylamino moiety in order to increase selectivity of the suicide substrates of Site 2. 


\section{References}

1. Silvestri, I., Lyu, H., Fata, F., Banta, P.R., Mattei, B., Ippoliti, R., Bellelli, A., Pitari, G., Ardini, M., Petukhova, V., Thatcher, G.R.J., Petukhov, P.A., Williams, D.L., Angelucci, F. (2020) Ectopic suicide inhibition of thioredoxin glutathione reductase. Free Radic Biol Med. 147, $200-211$.

2. Stanfield, R., Pozharski, E., Rupp, B. Comment on Three X-ray Crystal Structure Papers. (2016) J Immunol. 196 (2), 521-4.

3. Pearce, N.M., Krojer, T., Bradley, A.R., Collins, P., Nowak, R.P., Talon, R., Marsden, B.D., Kelm, S., Shi, J., Deane, C.M., von Delft, F. (2017) A multi-crystal method for extracting obscured crystallographic states from conventionally uninterpretable electron density. Nat Commun. $8,15123$.

4. Pearce, N.M., Krojer, T., von Delft, F. (2017) Proper modelling of ligand binding requires an ensemble of bound and unbound states. Acta Crystallogr D Struct Biol. 73 (Pt 3), 256-266.

5. Smart, O.S., Horský, V., Gore, S., Svobodová Vařeková, R., Bendová, V., Kleywegt, G.J., Velankar, S. (2018) Validation of ligands in macromolecular structures determined by X-ray crystallography. Acta Crystallogr D Struct Biol. 74(Pt 3), 228-236.

6. Johnson, T.W., Gallego, R.A., Brooun, A., Gehlhaar, D., McTigue, M. (2018) Reviving B-Factors: Retrospective Normalized B-Factor Analysis of cros Oncogene 1 Receptor Tyrosine Kinase and Anaplastic Lymphoma Kinase L1196M with Crizotinib and Lorlatinib. ACS Med Chem Lett. 9, 878-

883. 